\title{
FARM SIZE AND DIGITALIZATION: QUANTITATIVE APPROACH
}

\section{Iuliana Dobre ${ }^{1}$, Marius Capra ${ }^{2}$, Cristiana Adriana Costache ${ }^{3}$, Nicoleta Alexandra Dorobantu ${ }^{4}$}

\begin{abstract}
This paper takes into consideration the physical dimension impact of the quantitative description at the farm level over its economic performance. It is obvious that the dimension, if centred on different statistical intervals, generates different results, initiating the different types of potentiality that characterize the certain economic entity. The impact's capture was made through the registered data analysis, relevant for the enhancement of their quantitative characteristics.

Dimensional phenomenon was studied considering the data from the National Institute of Statistics (INSSE) of Romania, as well as statistical and economic analysis methods, proving that the dimension, in its actual structure, on different types of farms, can influence in a positive way the production and financial results. It is a generally accepted fact that, the physical dimension could be seen as the production capacity of the farm. Economic dimension or farm size is also an expression of farms' profit or turnover. In this condition the size is linked to economic performance. Economic dimension is usually characterized by inverse relation. Factors that determine a peculiar level of performance are usually specific in line to internal farm environment, respecting the used crops intensity or management under the factors of production.
\end{abstract}

Besides, level of digitalization represents another factor that have an important contribution to increase of farms' economic performances. Its influence represents the value generator at the farm level. So certain results derived

1 Iuliana Dobre, Ph.D., Associate Professor, Faculty of Agri-Food and Environmental Economy, Bucharest University of Economic Studies, Piata Romana no. 6, 010374 Bucharest, Romania, Phone: +40 722651 669, E-mail: iulya_dobre@yahoo.com

2 Marius Capra, Ph.D. Student, Faculty of Agri-Food and Environmental Economy, Bucharest University of Economic Studies, Piata Romana no. 6, 010374 Bucharest, Romania, E-mail: capramarius19@stud.ase.ro

3 Cristiana Adriana Costache, Ph.D. Student, Faculty of Agri-Food and Environmental Economy, Bucharest University of Economic Studies, Piata Romana no. 6, 010374 Bucharest, Romania, E-mail: costachecristiana19@stud.ase.ro

4 Nicoleta Alexandra Dorobantu, Ph.D. Student, Faculty of Agri-Food and Environmental Economy, Bucharest University of Economic Studies, Piata Romana no. 6, 010374 Bucharest, Romania, E-mail: dorobantunicoleta19@stud.ase.ro 
from previously conducted survey related to farmers' awareness towards the digitalization or, its presence at farm level was also done.

Key words: dimensions and economic performance, farm, digitalization, quantitative analysis.

JEL ${ }^{5}$ : O47, P47, Q12

\section{Introduction}

Paper is focused to the elements that constitute the farm concept in Romania, as well as on the allocation of human, financial and technical resources at farm level, what is generally correlated to cornerstone of farm development, the area of land where the farm has to be developed. The criteria for farms' classification have also to be harmoniously complemented to the link between the farm size and its level of performance. The current need to train the farmers derives from the premise that their competitiveness has to be as high as possible, while adapting to the market requirements through a long-term strategy. Both market analysis and ensuring its transparency are highly needed in order to anticipate the trends in line to the agricultural sector focused on market needs.

So, rural development programmes should be given priority. In order to be able to respond promptly to this priority, the European Union member states have succeeded in implementing certain programmes deeply focused to rural development, while adapting to their own capacities and challenges. These programmes may be established at national level, or, where appropriate, at regional level, as long as the European Commission approves and monitors their realisation. According to some research (Draghici, 2020) the member states should be obliged to set objectives in accordance with the specific intervention areas, to specify the used measures, and to carry out an assessment of the funding necessary to achieve those objectives.

\section{Methodology and Data Used}

In order to provide relevant results, in paper were used few methods, as are desk top research, comparative data analyses, and survey based on questionnaire. All results are presented in tables or by figures what facilitate their interpretation. Analysis covers recent data (respectively 2020-2021), or larger data sets starting from 2000. The used data refers to current situation of farms' economic and physical dimension, considering the relevant statistics gained from Romanian National Institute of Statistic. Some other national databases, scientific and professional literature were also consulted.

5 Article info: Original Article, Received: 24 $4^{\text {th }}$ April 2021, Accepted: 4th June 2021. 
After all, starting from idea that the degree of digitalization affects the farms' economic dimension, certain results have been derived from online survey based on questionnaire. Survey has to discover essential preferences and attitudes of stakeholders in ago-sector towards the digitalisation. Obtained results could serve as starting point in some other research or for establishment of some strategic directions due to digitalization issues. So, survey has to reveal the general interest of Romanian farmers against the introduction of new technologies at farm levels. The online survey was conducted through the Google Forms platform and certain social networks (Facebook and WhatsApp), while it was used the self-administered questionnaire. Questionnaire was distributed to representatives of different groups involved in agriculture. Survey was carried out at the sample of 520 respondents, and it was done within the period $31^{\text {st }}$ March - 21 ${ }^{\text {st }}$ April 2021.

\section{Results and Discussion}

\section{I) Farm size in the context of economic development}

\subsection{Farms typology according to production orientation and size}

In process of farms assessing, their quantitative elements related to physical size and obtained results (expressed in value) have be reconsidered. Ranking of farms should be based on the size of production area or number of animals used in their economic activity (Cvijanovic et al., 2014). These aspects manage to reflect the degree of concentration, using specific methods and applied according to the type of existing economy. In broad sense, the farm size is also described by the size of technical base and labour used in production processes (Eastwood et al., 2010). Economically, a particular dimension is relevant, especially those one which provides conditions for valuation of other types of available resources, as well as certain level of income. Clearly, after bringing up a larger dimension, it considers increasing the use of labour and capital, both fixed or working capital. Mentioned has direct and beneficial consequences towards the economic and social viability of farms. Depending on the farms' production orientation and typology, it could be assessed their economic dimension. Increasing the economic dimension requires the start from production structure and type of management used at farm, referring to strong correlation between them. 


\section{II) Technical and economic relevance of farm size to economic performance}

\subsection{Concepts and indicators}

Achieving rational level of concentration of agricultural production at the farm, while approving the exploitation of its advantages, but also avoiding possible shortcomings, should be the major desire of any farm. In order to determine the level of concentration of the required elements necessary for the farm production and obtained results, the term farm size is usually used in Romania (along the concept of size, also representing its physical approach).

Usually, the farm size refers to qualitative aspect of the production concentration process (result), as long as the size mirrors the quantitative side.

Behind the two notions is the concept of production intensiveness. It gives information about the degree of exploitation of basic resources through the successive capital investments. The farm size is expressed primarily by the size of estate (land area) or by the number of heads of animals (owned). There are also other indicators such are number of employees or used equipment (number of agricultural mechanisation, value of operating capital, etc.) that indirectly describe the farm size (Dobre, 2003). Farms that exceed certain frames of the economic dimension are considered professional, while they are usually observed by the RICA (Agricultural Accounting Information Network). Main goal of the RICA is to collect both production and farm economics data in order to determine farm revenues and prepare economic analyses of its business. Other farms are considered non-professional and they are not included in RICA observation. The minimum thresholds of farms' economic size are different for each EU Member State, reflecting to wide variety of agricultural structures encountered (Neuenfeldt et al., 2019).

\subsection{Calculation and classification by economic size of farms}

The physical size of farm is associated with the economic dimension, later being measured by the total or standard output, expressed in EUR. The size of farm also reflects to one of the important criteria for accessing European agricultural funds. Farms interested in accessing European non-refundable funds through the National Rural Development Programme (NRDP) should determine their economic size in order to prove eligibility for approaching to certain financing measure.

Thus, under the last NRDP for the period 2014-2020, the old concept of EDU (Economic Dimension Unit), which referred to the economic dimension of the farm determined by the standard gross margin, was abandoned. Besides the certain limits, method of the Standard Output (SO) is particularly relevant, determining the minimum farm size required for meeting the farm eligibility for funding. Mentioned 
classification is particularly relevant for its direct use in order to facilitate the sizing of support for investment in farms. Thus, the size of the farm represents the sum of all SOs derived from cultivated hectares or owned animals (Taragola et al., 2009).

Figure 1. Structure of farms

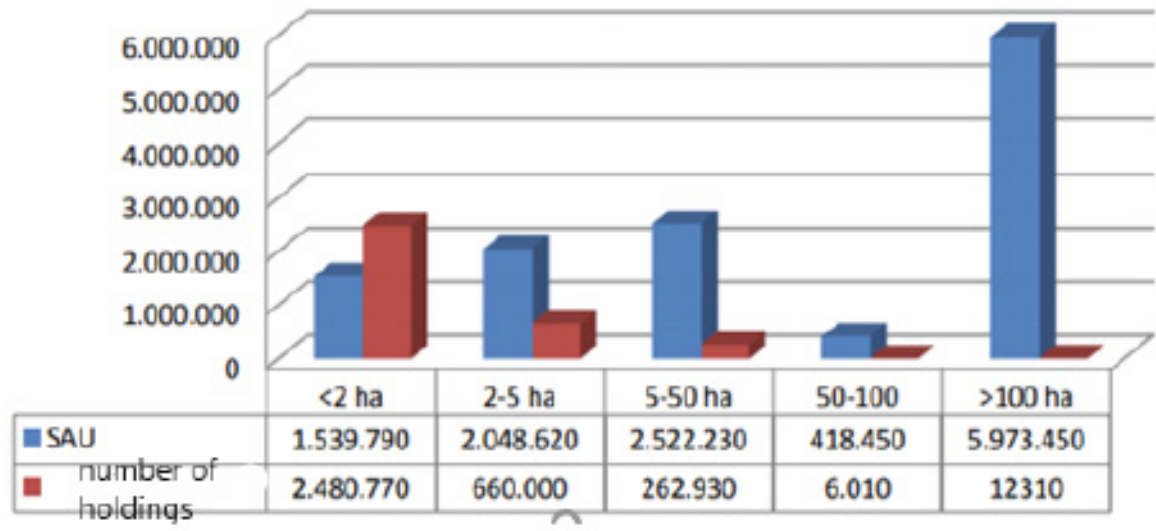

Source: European Commission, 2021.

According to previous figure (Figure 1.) the next aspects are relevant:

1. Subsistence farm has an economic size less than 1,999 EUR (expressed as SO), while it entirely produces for its own consumption.

2. The semi-subsistence farm has an economic size (SO) between 2,000-7,999 EUR. Besides their own consumption, this type of farms has also provided small part of production for market. They are usually specialized in pigs and poultry growing, rarely sheep breeding. Sometimes they are active in different crops growing too, as are fruits, field crops, or vegetables.

3. Small farm, with economic size (SO) between 8,000-11,999 EUR, are realizing more than $50 \%$ of its production at market. They are usually specialised in granivores growing (poultry or pigs), sometimes jointly with various field crops, or other animals.

4. The average farm is defined for the economic size (SO) between 12,000-250,000 EUR. Compared to other farm types, it markets its overall agricultural production.

5. Large farm has economic size (SO) larger than 250,000 EUR. It is marketing its entire production, and it is mainly specialised in cereal, oil, or protein crops production. 
Mentioned farms' types are determined towards their economic dimension, after assessing the cultivated areas and owned animals. Each type of crop or animal corresponds to certain SO value (Table 1.).

Table 1. Values of SO relative to cultivated area (for main crops, in EUR/ha)

\begin{tabular}{|l|l|}
\hline Wheat & 614.09 \\
\hline Barley & 529.44 \\
\hline Corn grain & 641.80 \\
\hline Green peas/beans & 533.76 \\
\hline Potato & $3,167.88$ \\
\hline Sunflower & 564.52 \\
\hline Fresh vegetables - in the field & $6,196.49$ \\
\hline Fresh vegetables - in the garden & $7,176.16$ \\
\hline Fresh vegetables - in greenhouses & $27,507.66$ \\
\hline
\end{tabular}

Source: AFIR, 2021.

The value of Standard Output for each crop represents the product of used number of hectares and SO coefficient for observed crop (AFIR, 2021). There will be done a simulation for the economic dimension of certain vegetable farm: Farm wants to assess its economic dimension in order to apply for European non-refundable funds. Thus, farm has the following production structure: 5 ha under wheat, 5 ha under vegetables in the field, 2 ha under tomatoes in protected area, 30 ha under corn and 10 ha under potatoes. Its economic dimension could be evaluated as: $5^{*} 614.09+$ $5 * 6196.49+2 * 27507.66+30 * 641.80+10 * 3167.88=140,001.02$ EUR (according to obtained sum, farm could be categorized as medium level farm, what allows approaching to European funds).

Table 2. Values of SO relative to number of grown animals (in EUR per head of certain category of animal)

\begin{tabular}{|l|l|}
\hline Cattles $<1$ year & 216.38 \\
\hline Cows and buffaloes for milk & $1,200.46$ \\
\hline Cattles $>=2$ years, male & 817.88 \\
\hline Cattles $>=2$ years, female & 801.37 \\
\hline Cattles $>2$ years & 515.85 \\
\hline Chicken for meat & 473.59 \\
\hline
\end{tabular}

Source: AFIR, 2021.

For all animal species grown at the farm next formula could be applied (AFIR 2021): SO $2013=$ no. head species $x$ OS species coefficient 
It will be done adequate example for determining the economic dimension of certain livestock farm. Farm have following production resources 10 dairy cows that calved 12 calves, 2 bulls over two years, 3 cattle over two years for slaughtering, 3 female bovine animals that calved 3 calves. Bovine are kept exclusively for the production of calves. Economic size of mentioned farm could be calculated as: SO $2013=$ $10 * 1,200.46+2 * 216.38+2 * 817.88+3 * 801.38+3 * 515.85=18,024.81$ EUR (according to this sum, farm could be categorized as medium-level, what allows it to be eligible for applying to European funds)

\subsection{Development and trends in dimensional structures in Romania and EU}

At first glance, the family farms could be seen as small or medium-sized. On the other hand, large and very large farms have a capitalist character, engaging the large level of external labour. Considering the economic situation in developed countries, it could be considered as totally contradicted. In these countries family farms are dominating and no longer could be considered as small or very small. Using the hitech equipment, they are possible to reach representative productivity, or they could cultivate more than ten, even hundred hectares. Family farms, both physically and economically, are rapidly moving to the group of higher-middle, large, or very large farms. At the national level, there is positive trend in their average size enlargement. Another trend concerns their specialization and diversification (Burcea et al., 2016; Popescu et al., 2016).

\section{III) Influence of the farms'size and specialization on their economic performances}

\subsection{Arguments for increasing the economic performance of the farm by size}

In Romanian agriculture, it is necessary to achieve good performance at farm level, what requires an active involvement of farmers and their linkage to available knowledge, or innovative and technological information. Although certain steps have been taken, around $75 \%$ of farms do not have yet the possibility to access digital expertise, what slows down the evolution of farms at national level. So, there are numerous of small and economically inefficient farms. Lack of modern technology at most farms is one of the reasons why the national productivity is declining. This underlines the necessity for new technologies introduction, as well as creation of safety nets for farmers during the crisis period or accidental events, what will significantly contribute in alleviating of any losses. Increasing the value of agricultural production based on knowledge and science, demonstrates that farmers who are facing the certain issues could achieve the success. So, enlargement of farm area allows easy introduction of contemporary technology, leading to benefits derived from safe and precise production methods independent of uncertainty. 


\subsection{Labour productivity and farm profitability}

Agriculture in Romania and EU countries is valued in different ways, referring to the level of farm performance and efficiency, its implication to the quality of farmers life, etc. Due to that there is a need to be focused on two main indicators profitability and labour productivity (Biddle, 2014). It is well known that economy is constantly changing, for this reason the profitability of agricultural production is often a sensitive issue for the most farmers. In each production system, the level of productivity differs along to production area assigned to each worker, but also to the level of utilization of certain means of production. Agriculture involves several material and economic elements. Farmer's managing skills play a particularly important role in achieving a reasonable long-term profit. Regarding the employment rate in agriculture, due to public interest in this economic activity, the situation is so discouraging.

Figure 2. Engaged labour in agriculture (in thousand AWU)

\begin{tabular}{|c|c|c|c|c|c|c|c|c|}
\hline \multicolumn{9}{|l|}{$\begin{array}{l}3500 \\
3000 \\
2500\end{array}$} \\
\hline \multicolumn{9}{|l|}{$\begin{array}{l}2500 \\
2000\end{array}$} \\
\hline 2000 & & & & & & & & \\
\hline 1500 & & & & & & 5 & & \\
\hline \multirow{2}{*}{\multicolumn{9}{|c|}{$\begin{array}{r}1000 \\
500\end{array}$}} \\
\hline & & & & & & & & \\
\hline & 1 & 2 & 3 & 4 & 5 & 6 & 7 & 8 \\
\hline Years & 2000 & 2010 & 2015 & 2016 & 2017 & 2018 & 2019 & 2020 \\
\hline $\begin{array}{l}\text { self-employed(1000 } \\
\text { annual work units) }\end{array}$ & 3415 & 1429 & 1151 & 1428 & 1345 & 1314 & 1243 & 1177 \\
\hline $\begin{array}{l}\text { Eemployee(1000 annual } \\
\text { work units) }\end{array}$ & 230 & 210 & 206 & 151 & 157 & 160 & 159 & 154 \\
\hline
\end{tabular}

Source: Authors' calculation based on INSSE, 2021.

Compared to the reference year (2000), in 2020 could be noticed significant decrease in engaged labour in agriculture (Figure 2.). Decrease is mainly caused by high share of elderly population, emigration of labour force to more developed countries, non-motivating agricultural income for young well-educated farmers, positive trends in the sector of services, etc. (Mateoc Sirb et al., 2014). In following figure are shown the areas of arable land available in Romania, potentially used in field crops production (Figure 3.). 
Figure 3. Cultivated areas under the main field crops

\begin{tabular}{|c|c|c|c|c|c|c|}
\hline & $\begin{array}{c}\text { Comm } \\
\text { on } \\
\text { wheat }\end{array}$ & $\begin{array}{l}\text { Corn } \\
\text { grain }\end{array}$ & $\begin{array}{c}\text { Sunflo } \\
\text { wer }\end{array}$ & Rape & $\begin{array}{c}\text { Autum } \\
\mathrm{n} \\
\text { potato } \\
\text { es }\end{array}$ & $\begin{array}{c}\text { Lucern } \\
\text { e }\end{array}$ \\
\hline 2015 UM: Ha & 2103815 & 2605165 & 1011527 & 367885 & 162886 & 364540 \\
\hline 2016 & 2130711 & 2580975 & 1039823 & 455953 & 153880 & 380248 \\
\hline 2017 & 2048134 & 2402082 & 998415 & 597967 & 140310 & 391114 \\
\hline 2018 & 2110520 & 2439842 & 1006994 & 632679 & 141336 & 408678 \\
\hline 2019 & 2162645 & 2678504 & 1282697 & 352622 & 142042 & 412861 \\
\hline
\end{tabular}

Source: Authors' calculation based on INSSE, 2021.

It could be seen (Figure 3.) that there are no considerable changes in the size of farms specialised in crop farming, with relatively modest fluctuations in last five years. Maximal areas are used in 2019, showing the presence of positive trend and sector evolution. The largest area under crops and the highest crop production were obtained in previous decades (before 1989), while in $21^{\text {st }}$ century there is a need for achievement of several qualitative objectives deeply directed to sustainable development. As result of better land cultivation and crops growing, over the last five years volume of plant production has evolved, with the certain level of correlation between the used technologies and increased labour productivity, what certainly left the positive mark on the entire sector (Figure 4.), (Popescu et al., 2017).

Few things could be noted in next figure. Primarily, production of main agricultural products (e.g. wheat, maize and sunflower), which cover the most of country's food security, has increased as results of farmers positive relations to the land caused by investments in technical progress, e.g. introduction of irrigation systems leads to increase in production of up to 2.3 times.

On the other hand, due to drought, produced quantity of autumn potatoes in 2019 is below the volume obtained in 2015. Initial investment in a hectare under potatoes reached the sum of 30,000 LEI (approximately 6,000 EUR), while the generated revenues were reached up to 40,000 LEI in favourable years (approximately 8,000 EUR). Lucerne has a significant share within the quality feed at livestock farms. 
Figure 4. Production of the main field crops

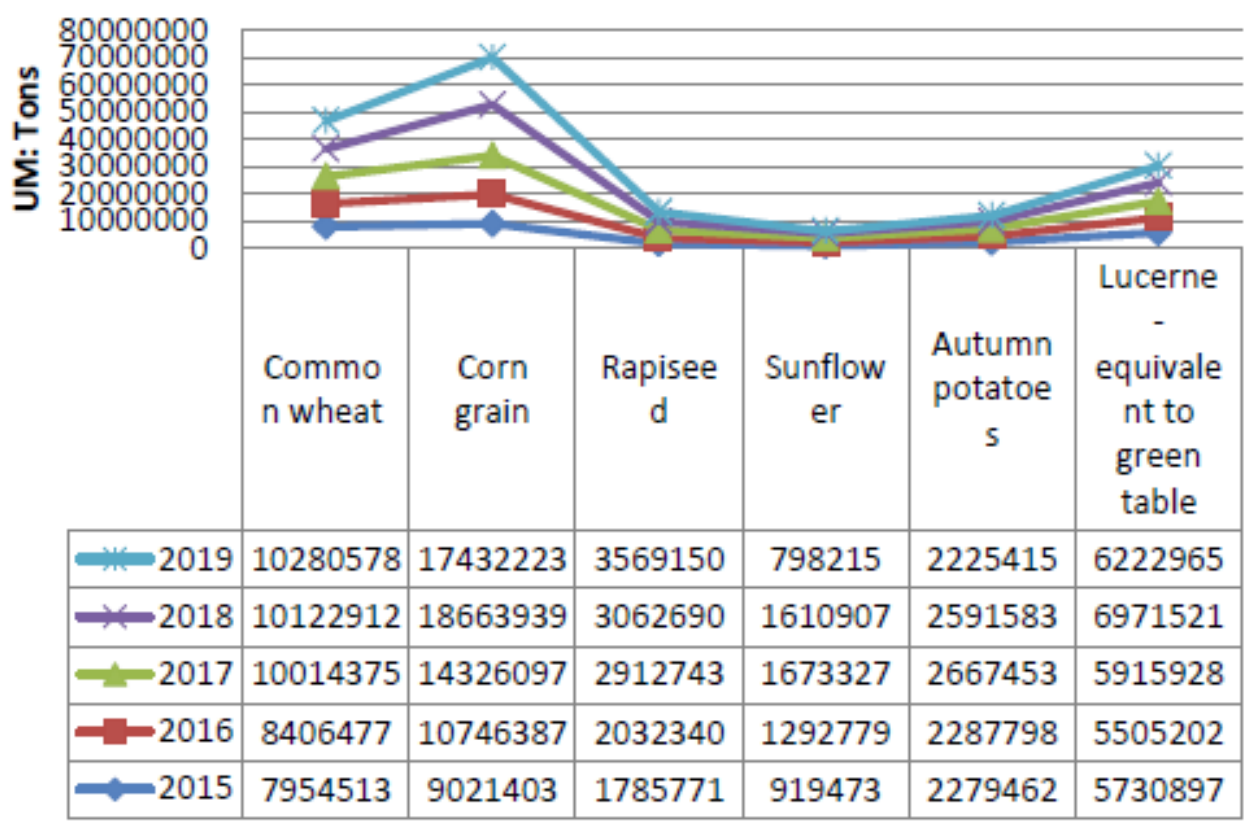

Source: Authors' calculation based on INSSE, 2021.

Subsistence farms out of constant financial sources have minimal chances for success and development, while they are especially vulnerable from the moment of land preparing for crop planting (initial investments), through the further care (occurred costs) up to the day of harvest. Therefore, investments that are allowing increase in production volume must remain among the priorities of agricultural farms. The belief that available natural resources are important factor within the climate system, playing the key role in agriculture, impose as imperative their rational use, what is the most often not easy to implement (Soare et al., 2016). The situation with COVID-19 pandemic in previous period has led to irreversible changes in Romanian labour productivity in agricultural sector. Implicitly it came to decline in value added within the structure of GDP (Nitu, 2020).

In scientific literature, profitability is usually expressed by appropriate net income, considering if available farm income could cover the average requirements derived from decent life conditions of all farm members.

\subsection{The area of digitalization on Romanian farms - A neoclassical approach}

It is widely accepted that the level of digitalization can contribute to increase in farm productivity, throughout the turnover growth, rise in profit and thus economic efficiency (Fielke et al., 2020). The size of farm has a decisive impact on the level of 
implemented and used technology in farm activities. There is a positive correlation between the farm size and farm need to implement digitalization in conducted activities (Schimmelpfennig, 2016). Even more, from the aspect of economy, decision to implement and use the robotics, IT and innovative technologies within the entire process of food production is more than justified, as it initiates the cut in labour or energy costs (agriculture is mostly labour intensive), provide the smart management under the available resources and inputs, as well as high level of economic efficiency (Subic et al., 2017).

By digitalizing agriculture, it is possible to increase the competitiveness of Romanian products, both nationally and internationally, as it is a factor that leads to increase in exports and brings the positive implications at macroeconomic stability (Ciurea, 2020). Digitalization is among key factors oriented, not only to strengthening of agricultural sector, but also to accomplishment of goals related to environment, climate and overall food chain sustainability, as it fits to all three aspects of sustainability (economic, ecological and social).

Moreover, sounds ideal to develop a European digital single market with predefined rules on ethics and competition in order to eliminate possible bottlenecks. In agrisector, the implementation of digitalization in certain production lines involves not only the use of state-of-the-art equipment or high-performance data systems, but also the change in mentality. So, digitalization has become a primary goal in contemporary society, promising several opportunities and benefits, as are optimization of activities, increase in productivity and decrease in costs. The growing interest in integrating the digitalization in farm could be also explained by the fact that there is a group of young people who have already taken over such agricultural organizations, while they prefer different kind of experience. Current Covid-19 pandemic just highlighted the need for digitalization, as digital economy could be joined by any economy from a distance (Low touch economy), (Gigauri, 2021).

In line to observed theme, during the April 2021 was made an on-line survey related the issue of digitalization towards the Romanian farmers preferences and attitudes. Survey involves the sample of 520 respondents, and it was done through the certain social networks, by the use of self-administered questionnaire. Some questions have been including the possibility of multiple answers, due to individual considerations of respondents (Dobre et al., 2021). According to general readiness to implement a new technology at the farm activities, more than $92 \%$ of respondents show positive interest (Figure 5.). 
Figure 5. Interest in new technology implementation at farm level

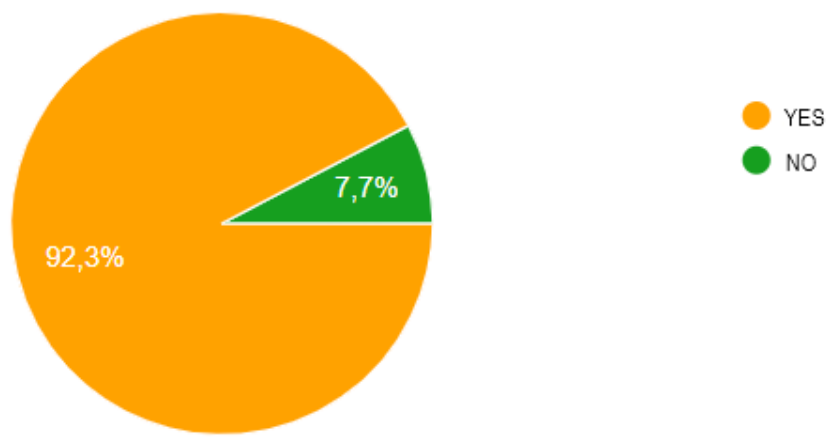

Source: According to Dobre et al., 2021.

Regarding the method of improving farms' economic performance (Figure 6.), it could be seen that almost $70 \%$ of respondents consider as essential the increase in agricultural land area, while implementation of innovative technology was considered important in more than $55 \%$. Other aspects such as change in management or cost reduction were considered important at almost $8 \%$, or more than $38 \%$ of respondents.

Figure 6. Used method in improving the farm performances

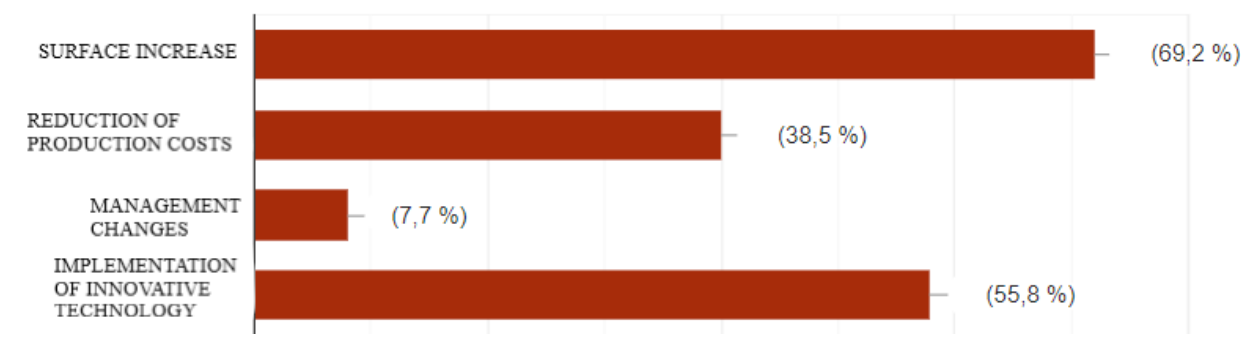

Source: According to Dobre et al., 2021.

Considering the time required for the introduction of new technology within the farm production processes (Figure 7.), it could be seen that more than half of respondents expect to implement the technology in next 5 years, while more than $30 \%$ of them expect this activity in next 10 years. Less than $4 \%$ of examinees state that they will be never in position to introduce the new technology at the farm. 
Figure 7. Required time-frame for the new technology implementation

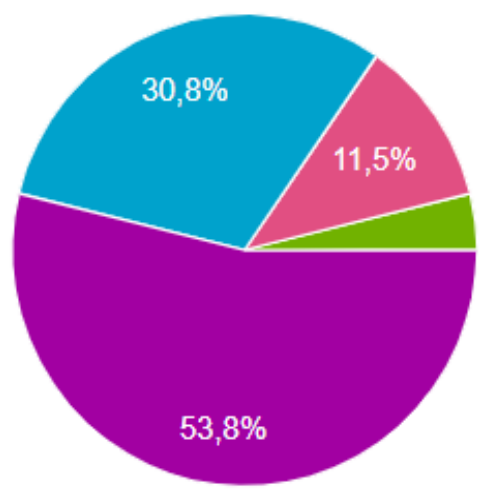

THE NEXT 5 YEARS

THE NEXT 10 YEARS

OVER 10

ONEVER

Source: According to Dobre et al., 2021.

However, it could be seen a growing interest in implementation of digitalization at the farms, as more than $67 \%$ of respondents give positive answer, while just more than $11 \%$ totally disagree the assumed idea (Figure 8 .). Meanwhile, there are more than $19 \%$ of indefinite examinees that have not yet thought about the digitalization of their farms.

Figure 8. Readiness for farm digitalization
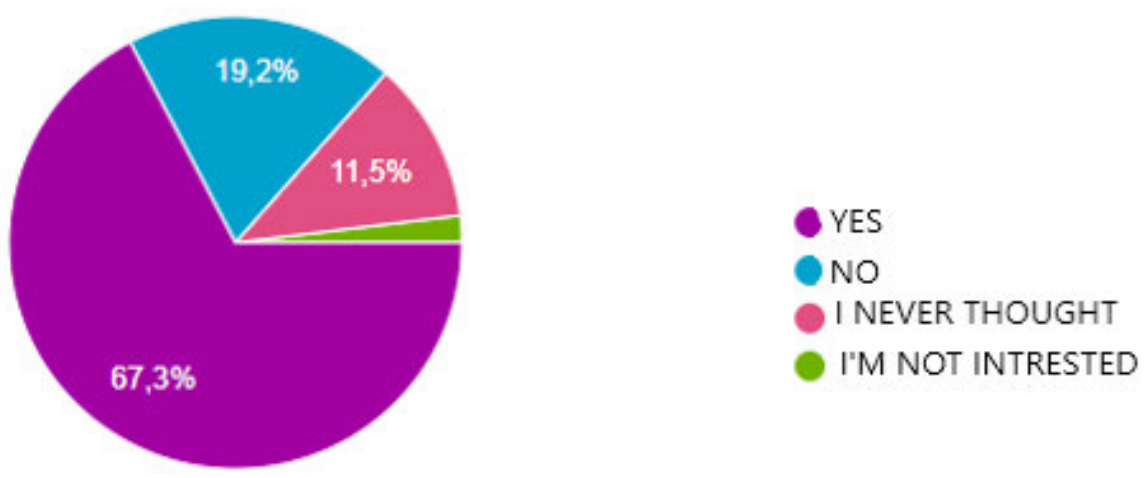

Source: According to Dobre et al., 2021. 
Figure 9. Agricultural knowledge and specialisation

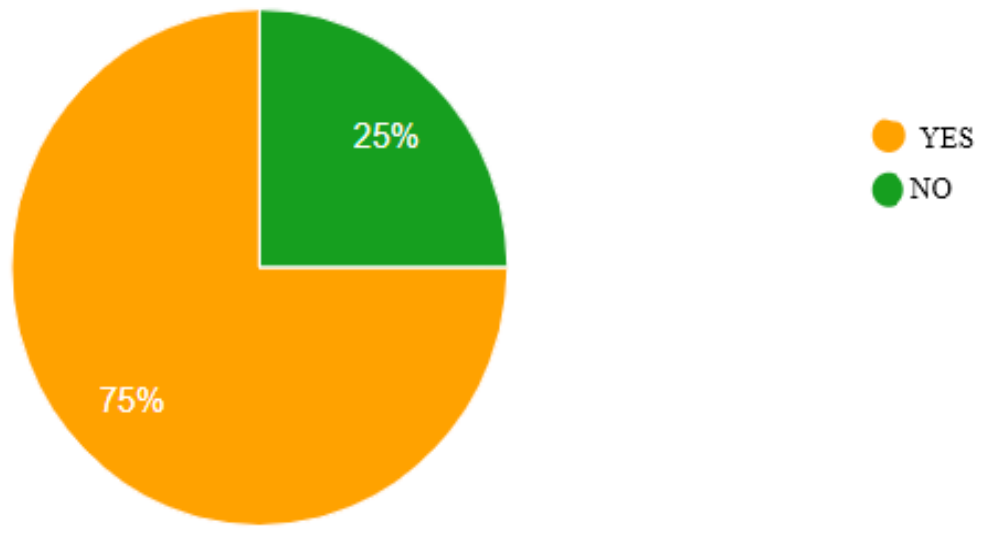

Source: According to Dobre et al., 2021.

A vast majority of respondents (75\%) confirm that they have been completed studies linked to agricultural specialization, while $1 / 4$ of them do not have formal knowledge in the field of agriculture (Figure 9.).

Figure 10. Access to EU funds
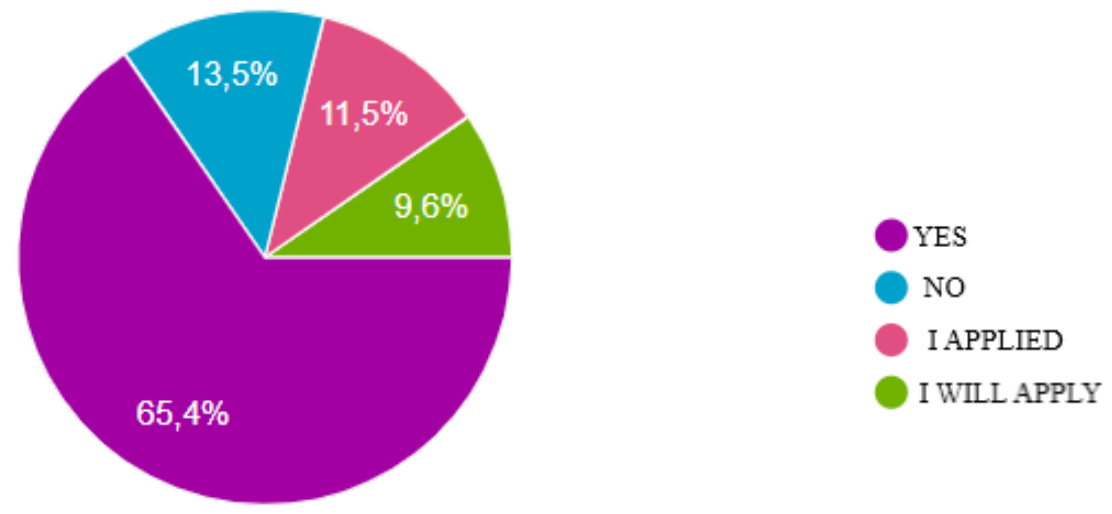

Source: According to Dobre et al., 2021.

In line to approach to available European funds turned to agriculture (Figure 10.), farmers are generally willing to use this opportunity (over the $65 \%$ ), despite the longer time required for administration and acceptance. Above $13 \%$ of examinees do not consider this opportunity as realistic alternative, while more than $11 \%$ of them have already the positive experience in applying. 


\section{Conclusions}

Farm size contributes to harmonic development of specific agricultural activities. As the involvement of more efficient mechanisation and equipment decrease the overall costs, they could in same time directly and significantly increase the farms' physical size. Related to size, there are defined five types of farms that correspond to standard output (SO), i.e. value of the farm economic dimension that concretely and coherently grouped them in order to attract the agricultural European funds.

Satisfactory farms' economic performance can be achieved only with the presence of certain factors such are: development of farmers' entrepreneurial skills for better economic and organisational management at the farm, establishment of long-term relations with suppliers, implementation of new technologies in line to increase the long-term yields' level, joining of small and medium-sized farms, as this step leads to decrease in their vulnerability, etc. Mentioned are the key factors of overall farm chain. Observing the Romania, available potentials are high and production factors are favourable, while there is lack of certain level of proactivity related to digitalization, new technologies and collaboration between the persons that share the same goals. So, it is necessary to boost the idea that identifying solutions in order to reactivate the wish to perform in the field of agriculture is crucial.

Overall conclusion linked to transformations caused by digitalization of farms will have an impact on all activities. In the accountancy, e.g. digitalization will facilitate the shift of paradigm, as it will allow the moving of professional focus even further from data management to analysis and consulting (accountancy deals with large datasets, which should be well harnessed, as they are helpful in discovering of farm opportunities, risks avoiding and, above all, in decision making). On other side, in agriculture it is expected to provide more efficient and competitive production that is adjusted to global goals towards the environment, climate, or sustainability of overall food chain. Related to farm digitalisation in Romania, farmers are generally aware of benefits it gives, as well as willing and ready for its implementation

\section{References}

1. AFIR (2021). Definitions and values of Standard Outputs in Romania. Portal of the Agentia pentru Finantarea Investitiilor Rural (AFIR), available at: https:// so.afir.info/home/about, retrieved at: $2^{\text {nd }}$ May 2021.

2. Biddle, J. (2014). Retrospectives: The Cyclical Behavior of Labor Productivity and the Emergence of the Labor Hoarding Concept. Journal of Economic Perspectives, 28(2):197-212. 
3. Burcea, M., Stoicea, P., Iova, R. A. (2016). Research on the evolution and the structure of farms in Romania. Scientific Papers Series Management, Economic Engineering in Agriculture and Rural Development, 16(2):49-54.

4. Ciurea, M. (2020). Considerations Regarding the Digitalization of Romanian Agriculture. Advances in Economics, Business and Management Research, 156:542-546.

5. Cvijanović, D., Subić, J., Paraušić, V. (2014). Poljoprivredna gazdinstva prema ekonomskoj veličini i tipu proizvodnje u Republici Srbiji. Statistical Office of the Republic Serbia (SORS), Belgrade, Serbia.

6. Dobre, I. (2003). Managementul structurii de productie in exploatatiile Agricole. Editura ASE, Bucuresti, Romania.

7. Dobre, I., Capra, M., Costache, C., Dorobantu, N. (2021). Survey data related to implementation of new technologies in agriculture. Internal documentation, Bucharest University of Economic Studies (ASE), Bucharest, Romania.

8. Dragichi, R. (2020). Despre digitalizare, în Europa şi în România. Portal of the AgriMedia, Bucharest, Romania, www.agrimedia.ro/articole/despre-digitalizarein-europa-si-in-romania, retrieved at: 24 ${ }^{\text {th }}$ March 2021.

9. Eastwood, R., Lipton, M., Newell, A. (2010). Farm size. In: Evenson, R., Pingali, P. (Eds.) Handbook of Agricultural Economics, vol. 4, chapter 65, Elsevier, Amsterdam, the Netherlands, pp. 3323-3397.

10. European Commission (2021). Facts related to structure of Romanian farms. Portal of the European Commission, Brussels, Belgium, available at: https:// ec.europa.eu/info/index ro, retrieved at: $2^{\text {nd }}$ May 2021.

11. Fielke, S., Taylor, B., Jakku, E. (2020). Digitalisation of agricultural knowledge and advice networks: A state-of-the-art review. Agricultural Systems, 180(102763):1-14.

12. Gigauri, I. (2021). New economic concepts shaping business models in postpandemic era. International Journal of Innovative Technologies in Economy, 1(33):1-11.

13. INSSE (2021). Basic set of data related to Romanian agriculture. Data portal of National Institute of Statistics (INSSE), Bucharest, Romania, available at: www. insse.ro, retrieved at: $25^{\text {th }}$ March 2021.

14. Mateoc Sirb, N., Mateoc, T., Manescu, C., Grad, I. (2014). Research on the labour force from Romanian agriculture. Scientific Papers Series Management, Economic Engineering in Agriculture and Rural Development, 14(1):215-218. 
15. Neuenfeldt, S., Gocht, A., Heckelei, T., Ciaian, P. (2019). Explaining farm structural change in the European agriculture: A novel analytical framework. European Review of Agricultural Economics, 46(5):713-768.

16. Nitu, F. (2020). Agricultura va avea cea mai mare scădere a valorii adăugate în PIB din ultimii cinci ani. Comisia Națională de Prognoză estimează un declin de 21\% pentru anul 2020. Portal of Ziarul Financiar, Bucharest, Romania, available at: $\quad$ www.zf.ro/eveniment/agriculture-will-have-the-biggest-drop-in-valueadded-in-GDP-19752489, retrieved at: $7^{\text {th }}$ April 2021.

17. Popescu, A., Alecu, I., Dinu, T., Stoian, E., Condei, R., Ciocan, H. (2016). Farm Structure and Land Concentration in Romania and the European Union's Agriculture. Agriculture and Agricultural Science Procedia, 10:566-577.

18. Popescu, G., Nicoale, I., Nica, E., Vasile, A., Andreea, I. (2017). The influence of land-use change paradigm on Romania's agro-food trade competitiveness: An overview. Land Use Policy, 61:293-301.

19. Schimmelpfennig, D. (2016). Farm profits and adoption of precision agriculture. Economic research report no. 217, Economic research service, USDA, Washington, USA, pp. 1-39.

20. Soare, E., Dobre, I., David, L. (2016). Economic analysis in vegetable sector of Romania. Scientific Papers Series Management, Economic Engineering in Agriculture and Rural Development, 16(4):333-338.

21. Subić, J., Jovanović, M., Despotović, Ž., Jeločnik, M. (2017). Possibilities of Applying Robotic Systems and Smart Sensor Networks in Integrated Agricultural Apple Production. In: Rodić, A., Borangiu, T. (eds.) Advances in Intelligent Systems and Computing, 540:269-281, Springer international publishing A.G., Cham, Switzerland.

22. Taragola, N., Bouters, S., Van Broekhoven, E. (2009). A new typology for horticultural holdings in Flanders, Belgium. In: $18^{\text {th }}$ international workshop on micro-economic databases in agriculture (Pacioli 18), Landbouw Economisch Instituut, Den Haag, the Netherlands, pp. 1-18. 